\title{
Development of self-management in pediatric inflammatory bowel disease: A qualitative exploration
}

\author{
Hilarious de Jesus*1, Ann Ooms ${ }^{2}$, Christine Norton ${ }^{3}$, Lesley Dibley ${ }^{1,4}$, Nicholas Croft ${ }^{1,5}$ \\ ${ }^{1}$ Children's Research Facility, Barts Health NHS Trust, London, UK \\ ${ }^{2}$ School of Nursing, Kingston University and St. George's University of London, London, UK \\ ${ }^{3}$ Department of Adult Nursing, King's College, London, UK \\ ${ }^{4}$ Department of Adult Nursing and Paramedic Science, University of Greenwich, London, UK \\ ${ }^{5}$ The Blizard Institute, Barts and the London School of Medicine and Dentistry, Queen Mary University of London, London, UK
}

Received: March 11, 2019

DOI: $10.5430 /$ jnep.v9n11p75
Accepted: August 12, 2019

Online Published: August 28, 2019

URL: https://doi.org/10.5430/jnep.v9n11p75

\begin{abstract}
Background: Self-management programs in pediatric chronic conditions, such as asthma and diabetes were effective in improving health-related outcomes. Similarly, self-management in the context of adult in inflammatory bowel disease (IBD) safely reduced healthcare costs. Nevertheless, evidence on self-management in pediatric IBD is scant. This study aims to explore self-management in pediatric IBD by exploring the childhood experience of IBD and how it is understood by the participants. Methods: Using a constructivist grounded theory approach, seven participants aged 8-17 years old were recruited in a tertiary metropolitan pediatric IBD center. Semi-structured interviews using topic guides and optional draw-and-write methods were used for data collection. Multi-level coding and constant comparison methods were utilised during data analysis.

Results: The pediatric IBD self-management theory described the phenomenon of self-management through the relationship of categories that emerged from the study. Self-management starts off as a parent-dominant process that progressed to a more autonomous form with increasing disease experience. The experience was described as filled with struggles and a developing sense of control in managing these struggles. Autonomous self-management developed from the interaction of information, insight and integration. Enablers and deterrents were the contextual factors that influenced the development of self-management. Conclusions: Establishing identity both as a psychosocial developmental task and a disease-specific task is the core of selfmanagement in childhood IBD. Future self-management programs should explore the role of structures around the child (family, school and healthcare systems) and the implementation of a proactive philosophy of involving children in managing their condition.
\end{abstract}

Key Words: Self-management, Pediatric IBD, Grounded theory, Qualitative study, Exploratory study, Adolescents, Self-care

\section{INTRODUCTION}

The increasing prevalence and the chronicity of childhoodonset inflammatory bowel disease (IBD) require healthcare systems to adapt to long term health demands. Selfmanagement has been explored as a potential means of addressing this need. A study of guided self-management in adults with IBD has been found to reduce hospitalisation and healthcare cost, whilst improving patient confidence without affecting patient safety. ${ }^{[1]}$ Self-management studies in other pediatric chronic conditions such as asthma ${ }^{[2]}$ and diabete ${ }^{[3]}$ have demonstrated positive effects on healthrelated outcomes. A Cochrane review of educational programs in pediatric asthma demonstrated positive effects in physiologic function, self-perception and reduction in use

*Correspondence: Hilarious de Jesus; Email: hedejesus@ yahoo.co.uk; Address: Children's Research Facility, Barts Health NHS Trust, London, UK. 
of health care resources. ${ }^{[2]}$ In the systematic review, the educational programs aimed at improving self-management included prevention and symptom management delivered via various modalities. Both asthma and IBD share the chronic, relapsing-remitting pattern, thus, self management interventions may share common ground too. Notably, the systematic review also indicated that information giving alone is not sufficient; a robust, well-targeted and defined intervention is necessary to demonstrate effectiveness. ${ }^{[2]}$ On the other hand, type I diabetes is another long term condition common among pediatric patients. A qualitative study of parent-child dyads revealed important dynamics on the shared responsibility for developing self-management skills. Conflict on adherence to interventions and developing autonomy of children are some of the important issues uncovered. Furthermore, the study described the movement of control from the parents to the young patients coinciding with developing maturity. It is highlighted that an effective intervention for enhancing self-management requires sufficient understanding of context and nuances.

Evidence in pediatric IBD is scant, ${ }^{[4]}$ and the dynamics of self-management in this specific population needs further exploration prior to implementation. It is important to take existing evidence on other contexts judiciously as there are crucial differences. Direct adaptation from adult IBD selfmanagement models into the pediatric setting without due consideration of developmental differences may be counterproductive. Similarly, direct adaptation of self-management in other pediatric chronic conditions may not always be suitable. One of the important differences between IBD and diabetes and asthma, for example, is the absence of a clear target behavior. In diabetes, glycaemic control is a clear target of management, while in asthma, prevention and drug management is the clear goal of treatment. ${ }^{[3]} \mathrm{IBD}$, contrastingly, includes medication adherence and dietary control as contributory to flare prevention but good adherence does not always guarantee continuous remission. ${ }^{[5]}$ Furthermore, IBD presents with taboo symptoms which impact social life differently than asthma and diabetes. ${ }^{[6]}$ Conversations about bowel movement and controlling urgency are not the same with conversations about calorie counts in diabetes and breathing exercises in asthma. Therefore, prior to developing intervention programs, an in-depth investigation of these nuances would be beneficial.

Part of the impediment in developing self-management interventions for pediatric IBD is the lack of conceptual clarity of self-management. ${ }^{[7]}$ Self-management studies in pediatric IBD have focused solely on medication adherence..$^{[1,8]}$ However, these two concepts - self-management and medication adherence, although related, are different. Most studies are quantitative and have focused on the identification of predictors of adherence, but findings are inconsistent. One study concluded that adherence is positively associated with disease severity and length of diagnosis, ${ }^{[9]}$ whilst others reported otherwise. ${ }^{[10,11]}$ These conflicting results can be addressed by using qualitative inquiry to explore nuances that are otherwise inaccessible through quantitative methods. The concept of pediatric self-management should expand beyond medication adherence. This can be achieved by clarifying the concept of self-management in the pediatric IBD context.

\section{MAterials AND MethodS}

The main aim of the study was to explore self-management as experienced by children and adolescents with IBD by gaining an in-depth understanding of childhood experience of IBD. Similarly, this study sought to provide a definition of self-management in the context of pediatric IBD.

\subsection{Design}

Constructivist grounded theory ${ }^{[12]}$ was the overarching methodology for the study. This approach produced a theory of self-management constructed through the accounts of participants, existing literature and the researcher's interpretation leading to a co-created understanding of the phenomenon.

\subsection{Sample/Participants}

As is common in grounded theory research, purposive sampling was used to recruit participants with the experience of interest who could likely support the study aims. Diagnosis of IBD for more than 6 months and willingness to participate were the inclusion criteria. Patients with cognitive disabilities and non-English speakers were excluded due to resource limitations. Participants had a range of disease management experience, including treatment with oral medications, biologic therapies and surgery. Some achieved remission immediately whilst others had more complex clinical pathways.

Seven participants were recruited in total. Three out of the seven participants opted to use the draw-and-write prior to interview. Data saturation guided the recruitment. By the fourth interview, saturation was noted as evidenced by repeated codes during analysis.

Consistent with grounded theory methodology, recruitment was a two-stage process. Initial exploratory interviews were completed with six participants. These were analysed to identify the emergent categories. Testing of the fit of the identified categories was conducted with one more participant using a more focused interview. 


\subsection{Data collection}

Interviews were conducted by HDJ with iterative feedback sought constantly from AO to improve technique and adjust questioning style. HDJ is a trained pediatric research nurse in his late twenties. To mitigate power-imbalances between adult researchers and young participants, various safeguards were used such as discussing dissent with young participants prior to taking assent, using warm up questions, requesting parental silence during interviews, if present, and giving options for home or hospital interview.

Interviews served as the main data collection method complemented with optional draw-and-write technique. ${ }^{[13]}$ Interview guides enabled flexibility of the questions to adjust to the participant's developmental age. All participants were offered the option to draw prior to the interview. Those who opted to do so were asked to draw 'what it feels like to live with IBD'. It was used as an elicitation technique for the interview by asking the participant to interpret their drawing using their own words. The optional use of this technique was a result of patient and public involvement (PPI) input during the design phase of the study. The technique also helped to 'anchor' the interview on concrete experiences which allowed for a more in-depth discussion with younger participants, who think in a more concrete, rather than abstract way.

\subsection{Pilot testing}

Two pilot interviews were conducted with a nine-year old and a 17-year old. Rapport was established using warm up questions. The nine-year old opted to draw-and-write prior to the interview, whereas the 17 -year old declined. The pilot provided a good sense of the relevance of the topic guide and allowed the researcher to adjust the style and the use of silences during the interviews. Pilot data is included in the analysis.

\subsection{Data analysis}

HDJ transcribed the recorded audio interviews verbatim, and coded the data. There were regular discussions between HDJ and $\mathrm{AO}$ during the analysis. Identifying details were removed from the transcriptions to maintain confidentiality, and valuable non-verbal information (e.g. shaking of the head and pointing on specific parts of the drawing) were added to the transcription to preserve the data authenticity. Analysis was executed using multi-staged coding, diagramming and theory building. Methodological and analytical memos were kept throughout the study to provide an audit trail. Reflexivity was exercised throughout the analysis by highlighting analytical streams during discussions between HDJ and AO. During analysis, data were managed with NVivo version 10.

\subsection{Ethical considerations}

Ethical approval was obtained from Southwest Exeter Research Ethics Committee ref: 15/SW/0334. Consent and assent were taken as per approved ethical standards. Furthermore, assignment of copyrights for drawings were sought prior to study participation.

\section{Results}

Seven participants were included in the study. Table 1 shows the characteristics and diagnoses of the participants.

Table 1. Characteristics of recruited participants

\begin{tabular}{|c|c|c|c|}
\hline Pseudonyms (Age) & Gender & Diagnosis (Years since diagnosis) & Brief description \\
\hline Fatima (9) & F & $\begin{array}{l}\text { CD* with orofacial granulomatosis } \\
\text { (5) }\end{array}$ & $\begin{array}{l}\text { Recently undergone bowel resection during the interview } \\
\text { period }\end{array}$ \\
\hline Arya (12) & $\mathrm{F}$ & Ileo-caecal CD* (4) & $\begin{array}{l}\text { In remission but known problems with medication } \\
\text { adherence }\end{array}$ \\
\hline Ali (10) & M & Ileo-colonic + Perianal CD* (3) & On Infliximab and a complex drug regimen to control IBD \\
\hline John (16) & M & Small bowel + Ileo-caecal CD* (3) & $\begin{array}{l}\text { Asymptomatic but endoscopy scores shows severe } \\
\text { inflammation }\end{array}$ \\
\hline Samuel (17) & M & Ulcerative colitis (3) & $\begin{array}{l}\text { Stopped attending school during exacerbation, currently } \\
\text { under control with Adalimumab }\end{array}$ \\
\hline Roxy (10) & $\mathrm{F}$ & $\begin{array}{l}\text { CD* with predominant colonic } \\
\text { distribution and strictures (3) }\end{array}$ & $\begin{array}{l}\text { Underwent surgical bowel resection, shifted from } \\
\text { Infliximab infusions to Adalimumab injections }\end{array}$ \\
\hline Sophie (17) & $\mathrm{F}$ & Ileo-colonic CD* (1) & Has a sister, also diagnosed with CD \\
\hline
\end{tabular}

*CD: Crohn's disease 
Forty-three codes were recorded as nodes on NVivo during the initial coding, which were then grouped into categories. The categories that emerged from the study were struggling, control, enablers and deterrents. Furthermore, the sub-categories of information, insight and integration as a function of effective self-management were identified.

\subsection{How do pediatric patients experience IBD?}

Imperative to providing a contextualised definition of selfmanagement was an understanding of the context of pediatric IBD. Struggling described the experience of pediatric IBD. It embodied the burden of the disease. It occurred when illness and its sequelae outweighed the coping reserves of the participants.

Misdiagnosis is cited as one of the main struggles.

I know I remember, I wasn't at this hospital, I was at [name of local hospital] ... They didn't know what the problem was. They gave me all kinds of things that could be, stupid stuff, that didn't make sense but they are so desperate just to know what it was. I think it was less popular then, Crohn's, so it's not [diagnosed]... stuck at it really. - Sophie, 17

Like, it [referring to 2 years of misdiagnoses] should've not taken that long. So that annoys me. - Arya, 12

IBD symptoms were also identified as struggle. Pain emerged as one of the main problematic symptoms. Roxy (aged 10) describes her pain as 'tummy being squashed', Ali (aged 10) describes it as 'knife in the stomach' and Fatima (aged 9) as 'spiked ball on her tummy'. Figure 1 shows the drawings used to describe pain.
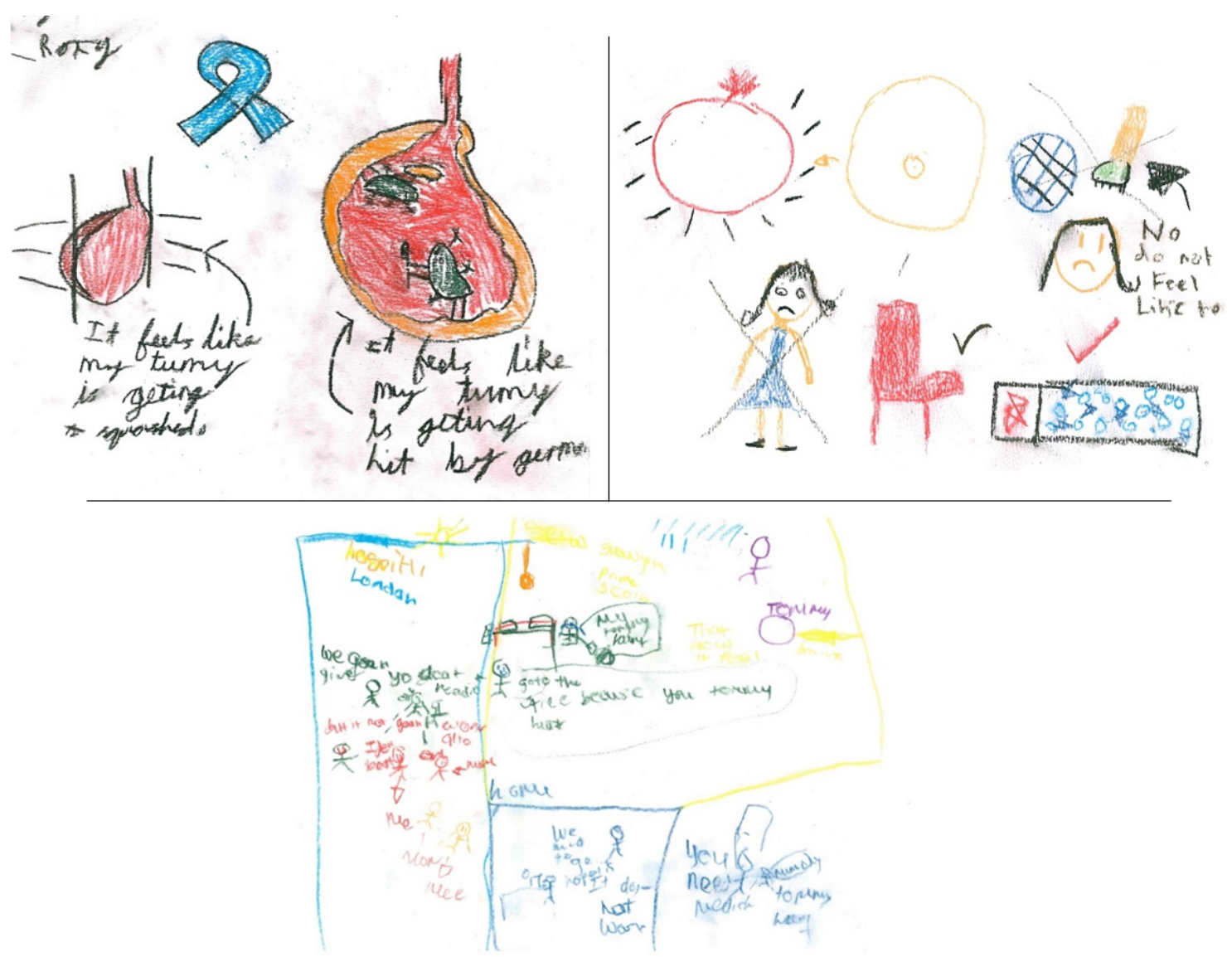

Figure 1. Drawings by the participants (Roxy - left, Fatima - Right, Ali - Below)

Fatigue was also reported by all participants but they described it as an under-recognised problem only made apparent by effective intervention.

It's just how I live. I live feeling tired. It's got nothing to do with the disease or anything. Roxy, 10

I think that's one [referring to fatigue] of the things as well. It's not [that] the energy goes 
away straight away. You felt drained, but you don't really notice it. . because you're not really doing anything to notice the difference of energy 'cause you're not doing anything at all. Once I felt better.. you could kind of feel the difference. - Samuel, 17

Interventions were also a source of struggles. Exclusive enteral nutrtion was reported by participants as being one of the most difficult interventions to cope with.

Not really nice. The first day I didn't really find it [referring to the sspecialised formula for CD] that well. I thought I was about to have the tube, but in the end, I just thought, I just drink it. John, 16

\subsection{What is self-management in the pediatric IBD con- text?}

The participants did not use the term 'self-management' during the interview. However, the researcher elicited selfmanagement skills in the participants' experiences by separately analysing who is the 'self' and what is 'management'. This was addressed by asking the young participants whenever they mention a disease-specific task in their IBD experience, how they deal with the situation.

The 'self' in pediatric IBD patients appeared to be a mutable and negotiated construct. When a patient was diagnosed early in life, the concept of self included parents and could vary depending on the circumstances. Younger patients started off as passive actors at the beginning of diagnosis, with most of the control assumed by the parents.

Interviewer: Tell me about it. What happened?

Ali: So basically... there's something in my bum [referring to anal fistula] and I have to go to my mum to show it. - Ali, 10

Sophie: When I was first diagnosed? I don't think so. I think I was very young. It was perfect the way they explained it to me. I think it was just enough to know that I was to take my medication. I have to go along with it...

Interviewer: So who was. . . taking control during that time? Was it your mum or your dad? Or anyone in your family?

Sophie: Both. My mum and my dad. - Sophie, 17

As participants gain experience with the disease, the concept of 'self' started to emerge into a more autonomous form. Published by Sciedu Press
Not worse and not better. It doesn't quite make a difference. I don't mind if she [referring to sister with Crohn's as well] comes with me. She goes with me; she goes without me. [She] doesn't stick to my appointments. - Sophie, 17

Arya talks about her desire to have surgery later.

My friend's dad [friend's name]. He had Crohn's disease. He's got part of his bowel removed. He doesn't have Crohn's disease anymore. Yeah. He's better... When I am older, I hope that I get it done, like Crohn's disease got better. I hope it doesn't hurt much. Like, I hope I can still do everything. - Arya, 12

Arya continued to ask about the operation and talked about her preference when she gets older, indicating her evolving concept of self. If given the power to decide on her future course of treatment, she would opt for surgery. These statements by the participants exhibited the transfer of control and development of identity as a young person with IBD.

The emergent category associated with management is control. Control referred to the perceived power to influence aspects of their lives in the context of developing autonomy and disease situation. Control included:

1) Engaging in behaviors to manage symptoms and other sequelae from the illness,

[when talking about how he managed his anxiety] Better than the enemas definitely. I do the injections myself. It's not something I enjoy doing. Sometimes it makes me feel anxious but not massively. It's controllable. I do it. - Samuel, 17

[when talking about how she manages abdominal pain] I used to lie in bed or sit down for a couple of hours. - Fatima, 9

2) Negotiation strategies,

[in the context of how she maintains social inclusion during flares] I did tell them, sometimes when I sit down, I told everybody, let's play sit down game like iSpy or board games. - Fatima, 9

[in the context of having Adalimumab injections] I was scared, and I was supposed to have two but I made them promise that I can have one today and the next one tomorrow. - Roxy, 10

3) Psychological adaptation 
I think when am feeling better, I have a better outlook of life. Although sometimes, it's not so much like that. Sometimes I focus on the negatives and think, oh, I could do that but what if this happens. So it's made me anxious. It's yin and yang. It's a bit of both. - Samuel, 17

Behaviors evolved in complexity as participants learned from their disease experience. Negotiation referred to actions by the participants to maintain influence over aspects of their lives. Psychological adaptation was about developing a positive mental attitude despite the burdens imposed by the disease or interventions.

\subsection{What factors affect self-management?}

Analysis of the interviews revealed two main categories associated with factors influencing self-management among pediatric patients with IBD. These were Enablers and Deterrents. As these labels imply, factors were divided into those which facilitate self-management and those that inhibit it.

Enablers cited by the participants included:

Supportive structures referred to social support systems around the participant that contributed positively to their disease management.

Sometimes, I forget but my mum reminds me and she lays them [my medicines] up with the table so that I don't forget. I don't like the taste, but I eat that 'cause it's gonna make me feel better. Fatima, 9

I: Do they [referring to school] know that you have Crohn's?

Roxy: Only my teacher does and she has IBD [referring to IBS], that's near to Crohn's... She has a type of disease almost like Crohn's... She says it's best to have honey water with ginger.Roxy, 10

Consistency of care is associated with the coordination of care information.

You wanna see the same person every time you come up but also when you have the bad news, you wanna be reassured that it's the right thing to do. - Samuel, 17

Participants reported a preference for interventions addressing specific, concrete behaviors rather than abstract goals. Specific behavior targets reinforce compliance.
It was really not a good taste so my mother, my mother, father gave me [money] for every cup [of specialised liquid formula] I tried... - Sophie, 17

I had a nutritionist and I had a few meetings with them and I had discussed what's gonna happen... after I finish Modulen.... so they basically started on plain stuff like bread. - John, 16

Deterrents to self-management included:

Unsupportive structures that negatively influenced achieving disease-specific tasks.

Everything was alright, and I went to college and then I had another flare. I was treated quite appallingly by the school to which I wasn't helped to deal with it. I didn't complete enough course work and rather than helping me to continue school stuff, they removed me from school... Then just a few months later, they pulled the plug and got rid of me. - Samuel, 17

The old one [referring to hospital that he felt mismanaged and misdiagnosed him] wasn't good, but this hospital was making me feel well. - Ali, 10

Inflexible attitudes of schools and poor medical diagnosis from healthcare systems contributed to psychological distress and poor health outcomes.

Social isolation occurs because of poor disease control.

When I was feeling ill again, I uh, cocooned myself again and didn't speak to anyone. I don't know. I just [don't] have anyone to speak to. No friends at all. It's not nice to think about. Samuel, 17

School is okay. But in school, I don't eat what food my friends are having. I don't like that. ... or go to the toilet a lot or have accidents in your pants. - Fatima, 9

[Eating] represents like holy things to us. And I was upset that I couldn't take part in it ... we say blessing before our food. I didn't say the blessing that everyone says before the food. Sophie, 17

Interestingly, dietary restrictions and fatigue as a part of the disease experience also created a different form of isolation religious isolation. Food, in this case, symbolises something more than nutrition. 


\subsection{What is effective self-management?}

Effective self-management occurred as an interaction of information, insight and integration.

Information was related to the experiences gained throughout the illness journey. This is typified by medication knowledge that progressed to compliance.

Interviewer: So let's go back to, how about medications? [Nurse's name] told me that you know all your medicines?

Fatima: Abidec, Sytron, Azathioprine, Omeprazole, Adcal D3 and yeah. - Fatima, 9

My parents. My mum, when I was first diagnosed, she used to write a list of everything I'm taking. ... but now ... I sort it out and take and put it all in a pot so it's all there ready for the week. - Samuel, 17

Younger participants exhibited a relatively accurate recall of their medicines. This knowledge of their medication was a stepping stone to compliance.

Insight was the development of awareness to differentiate effective behavior and strategies from ineffective ones. This was usually a result of trial-and-error experience.

Interviewer: So fizzy drinks and lentils, is there anything else that you are not supposed to eat?

Fatima: Some curries and I can't have high fibre food. - Fatima, 9

Interviewer: So how about the tablets, if you hate them, what keeps you taking them?

Arya: Just so that... cause before; I had to stay in hospital for ages, and there was like bad experiences and stuff... I don't wanna go back to hospital. -Arya, 12

Fatima learned from her experience that dietary choices were important in facilitating her remission. Arya exhibited a developing understanding that medication compliance and disease remission were closely related.

Integration was the assimilation of information and insight to be part of everyday living.

I had to keep on remembering to take them, but now I am used to it so it's part of my routine. It happen [s] in the morning, happen[s] at night... It just eventually was a part of me so I knew I have to have it and when I have to have them. John, 16
When I go for Infliximab, we'd like to stay... When I am having Infliximab... I have to have the machine for 2 hours and sometimes it makes you feel sleepy, so I sleep. Then you have to stay for an hour or 2 hours to see if I am ok... Fatima, 9

John's account reflected integration as a product of knowledge of his disease experience and the insight on effective routine behaviors. Fatima also demonstrated the developing dynamics between knowing about her Infliximab therapy and the modifications that she had to make to cope with it.

\section{Discussion}

The resultant categories are amalgamated into a unified theory shown in Figure 2.

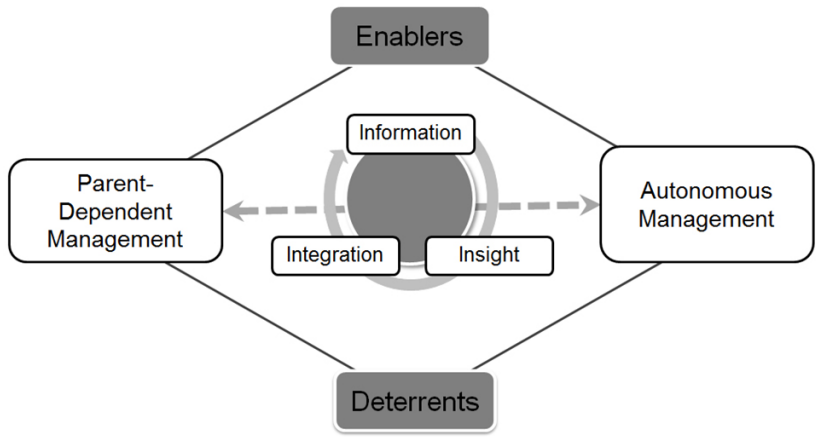

Figure 2. Pediatric IBD self-management theory

The diagram represents how self-management occurred among children and young people with IBD. At the point of diagnosis, self-management is a parent-dominant process. Throughout the disease trajectory and as the young IBD patients gained experience, control moved from the parent to the young person with IBD - the autonomous form of self-management. This movement is incremental and cumulative from increasing disease experience. Integration of information and insight describes how the autonomous form of self-management emerged. Enablers and deterrents are the contextual factors that surround this process.

The 'parent-dependent to autonomous continuum' indicated that self-management is a movement of control. The elasticity of the 'self' is exhibited through the surrender of control to parents. Young patients initially assume a passive role as exemplified by the narratives of Ali and Sophie. This is reflected in all the narratives of the participants, where parents took automatic responsibility at diagnosis. However, with increasing disease experience, young patients take a more proactive role. A notable parallel was seen in the study conducted by Sattoe ${ }^{[7]}$ argues where children with chronic conditions have an elastic concept of self. 'Self' changes 
depending on the circumstances. Similarly, in a study of selfmanagement among patients with type I diabetes, they described the movement of control with developing maturity. ${ }^{[3]}$ These incremental stages are characterised with labels such as parent-dominant, transitional and adolescent-dominant.

Aside from the shift of control, the continuum also symbolises how the development of identity as a normal psychosocial task coincided with disease-related task. One of the developmental tasks of healthy childhood, particularly adolescence, is the development of self-identity. ${ }^{[14,15]}$ Healthy adolescence is often depicted as one of the 'stormy periods'; exacerbated by struggles experienced by young patients with IBD. ${ }^{[16]}$ The struggles described by the participants - pain, fatigue, interventions - exemplify the 'stormy periods' of children with IBD. Children and adolescents with IBD need to reconcile not only "who am I as a person" but also, "who am I as a person with IBD". Corbin and Strauss ${ }^{[17]}$ referred to this as the biographical task of individuals suffering from chronic disease.

These findings have implications for both the parents and healthcare practitioners. The literature on self-management shows that parents ${ }^{[9]}$ and doctors ${ }^{[1,3,18]}$ have issues in shifting control to young IBD patients. The vulnerabilities of youth, paternalistic values and the uncertainties of the IBD trajectory are the potential reasons for this reluctance. However, this research shows that young IBD participants can and should be involved in managing their condition. Enabling emancipation can begin with medication knowledge progressing to not just facilitating routines but providing young IBD patients with information on the rationale for the interventions. Parents can have discussions with their children with IBD on how daily activities can be used to integrate management into their routine. Healthcare teams should actively engage young patients in understanding their condition using developmentally appropriate strategies. IBD nurses have a prime role to educate young patients, not just about their condition but also about their interventions.

The interaction among information, insight and integration describes how the process of control shifts from the parents to the more autonomous form. Information refers to the knowledge gained from the disease experience. Insight develops from the participant's ability to filter relevant information and use it to their benefit. Fatima's awareness of the link between diet and remission and Arya's realisation on medication adherence and relapse exemplified discerning insight. Lorig and Holman ${ }^{[19]}$ argued that critical to selfmanagement is problem identification, which is contingent on the ability to use information. Knowledge of the situation (information) and awareness of how it affects them (insight), constitute the elements of problem identification as a skill. Integration is information and insight applied to everyday living. It is manifested through the assimilation of disease-related tasks to everyday routine. One of the tangible manifestations of integration is medication management. It begins with information (knowledge of medicines and when to take them) reinforced by insight (why do I need to take them) and then enacted by integration (compliance by integrating it into daily routine). Integration can be viewed as a medical task ${ }^{[17]}$ and enactment of problem-solving skills ${ }^{[19]}$ of self-management.

Parents are in a prime position to enable integration, by helping their child with IBD to incorporate IBD interventions into their daily routine. As an initially parent-centric process, parents can facilitate this by identifying daily habits that can be useful to promote compliance (e.g. Sophie's use of a breakfast routine to remember her daily medicines). Also, healthcare practitioners can check whether integrated routines were correct and whether information and insight were accurate. During consultations, it is important to assess not just whether they are taking the medicines but also to understand how this was being enabled in daily life.

The diamond structure of Figure 2 indicates enablers and deterrents as contextual factors surrounding self-management. Enablers are factors that facilitated self-management while deterrents are inhibitors.

Self-management can be mitigated by enablers. This paediatric self-management model is different from adults due to the interplay of other structures such as family and school. ${ }^{[8]}$ Firstly, support to parents, especially during the initial phase of diagnosis, can be used to build up self-management skills. Secondly, support from schools significantly impacts selfmanagement. Mechanisms such as provision of toilet cards and food choices are seemingly trivial but can be a significant help among IBD patients attending school. ${ }^{[20]}$ Thirdly, care continuity is also crucial. Clarity of documented management plan and multidisciplinary case reviews are essential to care continuity, especially when patients see multiple healthcare personnel. Lastly, targeted behavioral interventions may be a better model to achieve significantly positive outcomes. This presents a potential area to exploit to induce compliance and help patients with the integration process.

Deterrent reduction will also positively contribute to selfmanagement. Institutions such as the school and hospital can be deterrents in developing self-management as evidenced by the narratives. Improving the efficiency of diagnosis and transfer of care from primary to specialist services is crucial for timely and appropriate management. Isolation was one of the emergent categories that negatively impacted 
self-management. It takes the form of social isolation or religious isolation. Diener ${ }^{[6]}$ talked about the 'disappearances' suffered by young IBD patients or 'concealing of self'. ${ }^{[16]}$ Development of identity is usually facilitated by peer relations, especially during adolescence; hence, isolation from peers can disrupt the development of identity.

\section{Strengths and limitations}

This qualitative exploration offered the first insight into selfmanagement in the pediatric IBD context that is beyond the concept of medication adherence. Furthermore, the study design also allowed for the voices of children and young persons to be heard rather than proxy accounts from parents. Arguably, this adds authenticity to the theory.

Nevertheless, there were some inherent limitations as well. Firstly, the sample size may appear to limit the study findings. Adequate sample size in grounded theory is demonstrated through the concept of data saturation. Practical and conceptual interpretations of saturation are conflicted in the literature. ${ }^{[21]}$ In this study, saturation is demonstrated by the lack of new categories emerging after the analysis of the initial six interviews. The decision to proceed to the 7th interview increased the confidence that saturation was reached. Secondly, the predominance of Crohn's disease diagnoses ( 6 out of 7 ) of the participants may limit the study findings. The difference of symptom and management of ulcerative colitis (UC) may limit the richness of the data. However, Samuel's account of his UC was in-depth. Furthermore, during analysis, once the data were grouped into categories, similar connections were observed. These may have mitigated that limitation. Lastly, the study was limited to the accounts of children and young patients. A better understanding of self-management may be uncovered by taking the familial accounts, especially, the parents. This limitation can be addressed in future research.

\section{Conclusion}

The self-management theory presented in this paper described self-management as it occurred in the paediatric context. Self-management included a dynamic notion of 'self' and gaining 'control' as management. 'Self' is an elastic concept that changes with progressive disease experience. This highlights the importance of parents and other social structures surrounding the care of a young IBD patient. Future research may also explore the changing concept of 'self' as a model in developing self-management programs.

The relationship of integration, information and insight explained how self-management evolved into a more autonomous and adult form. Sustainable models of selfmanagement should implement a proactive approach to fostering an empowered young person with IBD. Therefore, provision of contextualised information and including young patients during clinic consultation can facilitate this process. Using daily routines to serve as prompt for interventions may contribute to adherence.

Lastly, understanding the enabling and deterring factors are key to future intervention programs. Interventions that target social structures around the young patient with IBD, coordination of care and preventing psychosocial isolation are some of the potential key areas to explore. Future programs may explore enhancing support from parents, schools and healthcare systems in enabling the child to gain self-management skills as they mature

\section{ACKNOWLEDgements}

This study is done as part of the MRes studentship funded by the National Institute of Health Research (NIHR). This research was supported by the NIHR Collaboration for Leadership in Applied Health Research and Care North Thames at Bart's Health NHS Trust (NIHR CLAHRC North Thames). The views expressed in this article are those of the author(s) and not necessarily those of the NHS, the NIHR, or the Department of Health and Social Care.

\section{CONFlicts of InTEREST Disclosure}

The authors declare that there is no conflict of interest.

\section{REFERENCES}

[1] Barlow C, Cooke D, Mulligan K, et al. A critical review of self-management and educational interventions in inflammatory bowel disease. Gastroenterol Nursing. 2010 Jan-Feb; 33(1): 11-8. PMid:20145446 https://doi.org/10.1097/SGA.0b013e3181 ca03cc

[2] Guevara JP, Wolf FM, Grum CM, et al. Effects of educational interventions for self management of asthma in children and adolescents: Systematic review and meta-analysis. BMJ. 2003 Jun 14; 326(7402): 1308-9. PMid:12805167 https ://doi .org/10.1136/bmj . 326.
7402.1308

[3] Schilling LS, Knafl KA, Grey M. Changing patterns of selfmanagement in youth with type I diabetes. Journal of Pediatric Nursing. 2006 Dec; 21(6): 412-24. PMid:17101399 https ://doi .org/ $10.1016 / \mathrm{j} \cdot$ pedn .2006 .01 .034

[4] Hommel KA, Greenley RN, Maddux MH, et al. Self-management in pediatric inflammatory bowel disease: a clinical report of the North American society for pediatric gastroenterology, hepatology, and nutrition. Journal of Pediatric Gastroenteroly and Nutrition. 2013 Aug; 57(2): 250-7. PMid:23648790 https ://doi .org/10.1097/MPG. 
Ob013e3182999b21

[5] Benchimol EI, Fortinsky KJ, Gozdyra P, et al. Epidemiology of pediatric inflammatory bowel disease: A systematic review of international trends. Inflammatory Bowel Disease. 2011 Jan; 17(1): 423-39. PMid:20564651 https://doi.org/10.1002/ibd. 21349

[6] Diener JA. Everyone poops but no one wants to talk about it: the lived experiences of young people with inflammatory bowel disease [Master of Arts in Kinesiology and Health Studies on the Internet] Queen's University; 2011. Available from: http://hdl.handle.n et/1974/6638

[7] Sattoe JN, Bal MI, van Staa A, et al. Unraveling self-management: a delphi study exploring an ambiguous concept [PhD]. Erasmus University Rotterdam; 2015.

[8] Modi AC, Pai AL, Hommel KA, et al. Pediatric self-management: a framework for research, practice, and policy. Pediatrics. 2012 Feb; 129(2): e473-85. PMid:22218838 https://doi.org/10.1542/ peds. 2011-1635

[9] Reed-Knight B, Lewis JD, Blount RL. Association of disease, adolescent, and family factors with medication adherence in pediatric inflammatory bowel disease. Journal of Pediatric Psychology. 2011 Apr; 36(3): 308-17. PMid:20798185 https://doi.org/10.109 3/jpepsy/jsq076

[10] Mackner LM, Crandall WV. Oral medication adherence in pediatric inflammatory bowel disease. Inflammatory Bowel Disease. 2005 Nov; 11(11): 1006-12. PMid:16239847 https://doi.org/10.1 097/01. MIB.0000186409.15392.54

[11] LeLeiko NS, Lobato D, Hagin S, et al. Rates and predictors of oral medication adherence in pediatric patients with IBD. Inflammatory Bowel Disease. 2013 Mar-Apr; 19(4): 832-9. PMid:23446336 https://doi.org/10.1097/MIB. Ob013e3182802b57

[12] Charmaz K. Constructing grounded theory: a practical guide through qualitative analysis 2nd ed. London: Sage Publications; 2014.
[13] Bradding A, Horstman M. Using the write and draw technique with children. European Journal of Oncology Nursing. 1999 Sep; 3(3): 170-175. https://doi.org/10.1016/S1462-3889(99)8 0801-1

[14] Greig A, Taylor J, MacKay T. Doing research with children 3rd ed. Great Britain: Sage Publications Ltd; 2012.

[15] Erikson EH. Identity: youth and crisis. WW Norton \& Company; 1968.

[16] Savard J. Adolescents' and young adults' lived experience of living with an IBD and an ostomy [Master of Nursing]. University of Manitoba; 2007

[17] Corbin JM, Strauss A. Unending work and care: managing chronic illness at home. San Francisco: Jossey-Bass; 1988.

[18] Cooper JM, Collier J, James V, et al. Beliefs about personal control and self-management in 30-40 year olds living with inflammatory bowel disease: a qualitative study. International Journal of Nursing Studies. 2010 Dec; 47(12): 1500-9. PMid:20646707 https://doi.org/10.1016/j.ijnurstu.2010.05.008

[19] Lorig KR, Holman HR. Self-management education: History, definition, outcomes, and mechanisms. Annals of Behavioral Medicine. 2003 Aug; 26(1): 1-7. PMid:12867348 https://doi.org/10.1 207/S15324796ABM2601_01

[20] Schwenk HT, Lightdale JR, Arnold JH, et al. Coping with college and inflammatory bowel disease: implications for clinical guidance and support. Inflammatory Bowel Disease. 2014 Sep; 20(9): 1618-27. PMid:25105948 https://doi.org/10.1097/MIB.0000000000 000124

[21] Guest G, Bunce A, Johnson L. How many interviews are enough? an experiment with data saturation and variability. Field methods. 2006 Feb; 18(1): 59-82. https://doi.org/10.1177/1525822X0527 9903 